\title{
MOLECULAR AND MORPHOLOGICAL IDENTIFICATION OF STREPTOMYCES SP. NRC-88 NOVA SPECIES AS $\beta$-LACTAMASE INHIBITOR FOR PHARMACEUTICAL APPLICATION
}

\author{
HASSAN MOHAMED AWAD ${ }^{1 *}$, MOUSA 0 GERMOUSH ${ }^{2}$ \\ ${ }^{1}$ Department of Chemistry of Natural and Microbial Product, Pharmaceutical Industry Division, National Research Centre, Dokki, \\ P.0.12622, Cairo, Egypt. ²Department of Biology, College of Science, Aljouf University, Sakaka, Al-Jouf, Kingdom of Saudia Arabia. \\ Email: awadmhassan@yahoo.com
}

Received: 23 May 2017, Revised: 21 August 2017 and Accepted: 02 September 2017

ABSTRACT

Objective: Clavulanic acid (CA) is a vital agent in the treatment of bacterial infections since it is a potent inhibitor of an extensive variety of $\beta$-lactamase enzymes. Its production from Streptomyces strains is fact of expanding clinical significance. This study aimed to isolate and characterize a promising Streptomyces $(\mathrm{S})$ species strain which produced an effective $\beta$-lactamase inhibitor.

Methods: Streptomyces sp. NRC-88 was isolated from an Egyptian soil sample. The phenotypic and phylogenetic examinations of $16 \mathrm{~S}$ rRNA gene were investigated. The active metabolite of this strain (CA) was determined by particular synergistic bioassay, spectrophotometric assay, recognized by thin layer chromatography, and structure of the CA affirmed by high-performance liquid chromatography (HPLC) method.

Results: A phylogenetic examination of the $16 \mathrm{~S}$ rRNA gene sequence of the NRC-88 strain consistent with conventional taxonomy was carried out, and confirmed that the strain NRC-88 was most similar to S. aburaviensis S-66 (99\%). The active metabolite of this strain (CA) was determined by different methods and confirmed the structure of the CA by the HPLC method. It produced up to $87 \mathrm{mg} / \mathrm{l}$ in a specific CA production medium.

Conclusion: A new species of Streptomyces sp. NRC-88 isolated and recognized by phenotypic and genotypic proof. This strain suggested the name, Streptomyces sp. NRC-88 (accession number KM014489). It was able to produce CA as the $\beta$-lactamase inhibitor.

Keywords: Isolation, Streptomyces sp. NRC-88, Phenotypic and phylogenic identification, Clavulanic acid production.

(C) 2017 The Authors. Published by Innovare Academic Sciences Pvt Ltd. This is an open access article under the CC BY license (http://creativecommons. org/licenses/by/4. 0/) DOI: http://dx.doi.org/10.22159/ajpcr.2017.v10i10.20201

\section{INTRODUCTION}

The diseases caused by microorganisms are considered to be serious threats against people's health worldwide and a great deal of money is spent to treat them. Genuine contaminations brought about by microorganisms that have turned out to be impervious to normally utilize antitoxins have turned into a noteworthy worldwide social insurance issue in the $21^{\text {st }}$ century [1].

The $\beta$-lactam antibiotics are a standout among the most prevalent classes of antibacterial operators, whose system of activity is by means of the hindrance of bacterial cell divider union [2]. Not long after the use of the $\beta$-lactam antibiotics, the resistance of $\beta$-lactam antibiotics is associated with inactivation of the $\beta$-lactam structure due to the opening of the $\beta$-lactam ring by $\beta$-lactamase produced by bacteria [3]. Microorganisms which are impervious to specific antitoxins are progressively causing difficult issues in the treatment of irresistible maladies [4]

One of the techniques utilized by this gathering of bacteria to resist against $\beta$-lactam antibiotics is the generation of a $\beta$-lactam hydrolyzing enzyme $\beta$-lactamase, which has the capacity kill these anti-infective agents by severing the $\beta$-lactam ring [5]. Along these lines, to defeat this resistance, $\beta$-lactamase inhibitors are frequently utilized as a part of conjunction with $\beta$-lactam antibiotics as these mixes maintain the debasement of these antibiotics and increment the adequacy of these medications [6].

CA is a powerful inhibitor of an extensive variety of $\beta$-lactamase from pathogenic living beings which are in charge of the defense of microorganisms against $\beta$-lactam antibiotics [3]. CA or clavulanate, is commercially used along with amoxicillin or ticarcillin (augmentin), which is $\beta$-lactam antibiotics with high levels of antibacterial activity and this combination has been listed as an important and very successful antibacterial agents in preventing infections due to Gram-positive
(Staphylococcus sp.) and Gram-negative (Klebsiella sp., Hemophilus sp., Proteus, Shigella, Pseudomonas). $\beta$-lactamase-producing pathogens in the WHO list of essential medicines (2015). Amoxicillin + CA is most commonly prescribed out by fixed dose combinations of all antimicrobials and can be of a very effective alternative treatment against the deadly multidrug resistant Gram-negative bacteria [7]. In Brazil, medicines containing amoxicillin and potassium clavulanate are mainly produced by Glaxo-SmithKline Beecham Farmacêutica Laboratories under the name of clavulin or Augmentin with reported global sales of $>\$ 2.1$ billion [5].

Microorganisms fill in as alluring assets, attributable to their capacity to coordinate significant items with novel structures and activities [8]. Soil, specifically, is a seriously abused biological specialty of the inhabitants of the bacteria domain. Actinomycetes demonstrated an uncommon capacity to create possibly novel, clinically valuable, secondary metabolites, for example, anticancer, anti-infection agents, cell reinforcements, antivirals, antibacterial, and enzymes [9-11].

CA was first produced by S. clavuligerus [12]. Jensen and Paradkar [13] mentioned that CA itself is even more restricted, with only four producing Streptomycetesspeciesreported todate.ThesestrainsareS.clavuligerus [12], S. jumoninensis [14], S. katsurahamanus [15] Streptomyces sp. [16] More recently, Streptomyces sp. NRC-35 [17], Streptomyces sp. NRC-77 [18] and Streptomyces sp. MuNRC-77 [19]. This study presents the isolation and characterization of a promising strain of Streptomyces species producing a $\beta$-lactamases-inhibitor.

\section{METHODS}

\section{Microorganisms}

Strain NRC-88 was isolated from an Egyptian soil sample by screening program. The new identified Streptomyces species-produced CA. This 
strain was deposited in the Actinomycetes Culture Collection, National Research Centre, Cairo, Egypt. A resistant strain of Escherichia coli, at $25 \mu \mathrm{g} / \mathrm{ml}$ Penicillin-G (Sigma, St. Louis, USA), was used as a test strain for CA production. These strains were stored at $-80^{\circ} \mathrm{C}$ in $50 \%$ glycerol for further studies.

\section{Streptomyces isolation and cultivation conditions}

Streptomyces isolation and CA detection

Thirty Streptomyces isolates have been isolated from different Egyptian soil samples. Strain NRC-88 was isolated using serial dilution plate technique on two different media. The first medium is actinomycetes isolation agar medium (Difco, NJ, USA) which composed of (g/l): Glycerol - 5; sodium propionate - 4; sodium caseinate - 2; $\mathrm{KH}_{2} \mathrm{PO}_{4}$ - 2; asparagine - 0.1; $\mathrm{MgSO}_{4} .7 \mathrm{H}_{2} \mathrm{O}-0.1$ and $\mathrm{FeSO}_{4} .7 \mathrm{H}_{2} \mathrm{O}-1 \mathrm{mg}$; agar - 15 , at $\mathrm{pH}$ 7.0. The second medium is Streptomyces medium which consists of (g/l): Glucose - 5; L-glutamic - 4; $\mathrm{KH}_{2} \mathrm{PO}_{4}-1 ; \mathrm{MgSO}_{4} .7 \mathrm{H}_{2} \mathrm{O}-0.7 ; \mathrm{NaCl}$ - 1; $\mathrm{FeSO}_{4} \cdot 7 \mathrm{H}_{2} \mathrm{O}$ - $1 \mathrm{mg}$; agar - 25 . The isolation media supplemented with $25 \mu \mathrm{g} / \mathrm{ml}$ of penicillin $\mathrm{G}$ and cycloheximide $(50 \mu \mathrm{g} / \mathrm{ml})$ to minimize the bacterial and fungal contamination, respectively, and then, incubated at $28^{\circ} \mathrm{C}$ for 7-10 days [17]. The isolates were primarily tested for their ability of $\beta$-lactamase inhibitor by the specific synergistic bioassay [20] using a resistant test strain of E. coli. CA was detected by thin-layer chromatography (TLC) [21]. It was determined by spectrophotometric method at $312 \mathrm{~nm}$ after derivatization with imidazole according to Bird et al. [22], and confirmed the structure of the CA by high performance liquid chromatography (HPLC) assay [23]. The promising isolates, which showed the maximum CA production, were selected for further identification.

\section{Production medium and cultivation conditions}

Strain NRC-88 was cultivated in Erlenmeyer flask $250 \mathrm{ml}$ containing $50 \mathrm{ml}$ (production medium) on rotary shaker Innova 4080 (New Brunswick, NJ, USA) at $200 \mathrm{rpm}$ and $28^{\circ} \mathrm{C}$ for 6 days. The production medium composed of (g/l): Soy bean meal - 30; soluble starch - 47; $\mathrm{FeSO}_{4} \cdot 7 \mathrm{H}_{2} \mathrm{O}-0.1 ; \mathrm{KH}_{2} \mathrm{PO}_{4}-0.1 ; \mathrm{pH} 6.5 \pm 0.2$. The inoculation was carried out using a spore suspension of NRC-88 strain slanted on International Streptomyces Project (ISP) 2 medium. The culture broth was separated from the mycelium by centrifugation at $8000 \mathrm{rpm}$ for 10 minutes. The supernatant was sterilized by filtration and used for the evaluation of the inhibitory activity, which was carried out using the above mentioned three methods.

\section{Composition of the culture media used for identification studies}

The media composition and the cultivation conditions were performed according to Shriling and Gottlieb [24].

\section{Cultural, morphological, physiological, and biochemical analysis} of strain NRC-88

Cultural characteristics describe the growth, the color of the aerial mass, and the substrate mycelium, and the soluble pigment of the strain on different ISP media. These characteristics of strain NRC-88 were observed on the $7^{\text {th }}$, the $14^{\text {th }}$, and the $21^{\text {st }}$ day for mature cultures grown on various media followed the guidelines adopted by ISP [24]. The color of the aerial mass, the substrate mycelium, and the soluble pigment were visually estimated using Stamp Color Key based on the computer color wheels [25].

Morphological properties include both spore chains and spore surface of the isolated strain. The spore chains of strain NRC-88 were determined by a light microscope (Model SE. Nikon Inc., NY, USA). This was done using the cover slip technique in which individual cultures (14 days age) were transferred to the base of cover slips buried in Bennett's medium for photographs. The spore surface of strain NRC88 was observed under transmission electron microscope (TEM) Zeiss EM 10 (Zeiss, Oberkochen, Germany) from the culture on 21 days of incubation [24]. These characters and photos of the Streptomyces isolate were compared to the similar Streptomyces species in Bergey's Manual of Determinative Bacteriology Ninth edition [26] and Bergey's
Manual of Systematic Bacteriology [27] to identify the isolate to the species level.

The physiological tests included starch hydrolysis, gelatin liquefaction, skim milk coagulation, melanin pigment production, and nitrate reduction. The starch hydrolysis, the growth on gelatin and skim milk were tested [24] using special media described above. The production of a melanin pigment was observed on media ISP 1, 6, and 7 after 7-10 days and nitrate reduction was tested on nitrate broth medium (Fluka, NY, USA) following to the directions given by ISP [24].

The chemotaxonomy included the cell wall analysis and carbon sources utilization. Diaminopimelic acid (LL-DAP) isomers in the cell wall were analyzed by paper chromatography using the method of Lechevalier and Lechevalier [28]. The ability of the strain to utilize different carbon sources was examined on basal medium ISP 9 to which separatelysterilized carbon sources were added to a final concentration of $1.0 \%$ using glucose as positive control. The plates were incubated at $28^{\circ} \mathrm{C}$ and the growth was noticed after 7,14, and 21 days.

\section{Molecular identification and phylogenetic analysis of strain NRC-88} Extraction of Streptomyces genomic DNA

The strain was grown on a slant of the actinomycete isolation agar medium for 7-10 days at $28^{\circ} \mathrm{C}$. Two $\mathrm{ml}$ of spore suspension were inoculated in the ISP 2 broth medium and incubated on incubator shaker Innova 4080 (New Brunswick, NJ, USA) at $200 \mathrm{rpm}$ on $28^{\circ} \mathrm{C}$ for $24 \mathrm{hrs}$ to form pellets of vegetative cells. Total genomic DNA preparation was carried out using the method of Lee et al. [29]. The collected pellets were left to dry and dissolved in a suitable volume $(100 \mu \mathrm{l})$ of TE buffer $(100 \mathrm{mmol} \mathrm{NaCl}$, $1 \mathrm{mmol}$ ethylenediaminetetraacetic acid, $100 \mathrm{mmol}$ tris- $\mathrm{HCl}, \mathrm{pH} 8.00$ ), or deionized water and stored at $-20^{\circ} \mathrm{C}$. An aliquot was analyzed by agarose gel electrophoresis (1.5\%) to assess the DNA concentration.

\section{Polymerase chain reaction (PCR) amplification and sequencing}

The PCR reactions were carried out in $0.2 \mathrm{ml}$ Eppendorf tubes in total volume of $25 \mu$ l. The amplifications were performed in a Gene AMP, PCR system 9700, PE Applied Biosystemes, (Perkin Elmer, Ohio, USA). The sequencing Streptomyces-specific PCR primers used were StrepB, 5' - ACA AGC CCT GGA AAC GGG T-3' (forward) and StrepF 5'-ACG TGT GCA GCC CAA GACA-3' (reveres) using Biolego BV software (Biolegio, Nijmegen, the Netherlands). These primers were used for the amplification of $16 \mathrm{~S}$ rRNA fragments from genomic DNA isolated Streptomyces [30].

The PCR reaction mixture $(25 \mu \mathrm{l})$ contained PCR beads (Amersham Bioscience Europe $\mathrm{GmbH}$, Freiburg, Germany), $0.5 \mu \mathrm{l}$ from each primer StrepB and SterpF and $2 \mu$ of template genomic DNA up to final volume $25 \mu \mathrm{l}$ reached by deionized water. Amplification was performed with an initial denaturation step of 3 minutes at $94^{\circ} \mathrm{C}$ and then 35 cycles of $\left(60\right.$ seconds denaturation at $94^{\circ} \mathrm{C}, 30$ seconds at $59^{\circ} \mathrm{C}$ for primer annealing and 60 seconds at $72^{\circ} \mathrm{C}$ for primer extension) and kept at $72^{\circ} \mathrm{C}$ for 7 minutes to complete extension.

Electrophoresis of the PCR products was carried out on $1 \%$ agarose gel containing ethidium bromide $(0.5 \mu \mathrm{g} / \mathrm{ml})$, to ensure that a fragment of the correct size had been amplified [31] and detected by a Gel documentation system (Alpha-Imager 2200, CA, USA). Amplified 16S rRNA fragments were purified using the QIAquick PCR purification kit (Qiagen, Hilden, Germany).

Sequencing of the purified PCR product was carried out by ABI Prism 377 DNA Sequencer (Perkin Elmer, Ohio, USA) with the reaction kit Big Dye ${ }^{\circledR}$ Terminator v3.1. Cycle sequencing ready reaction (Applied Biosystems, Foster City, USA) and the universal primers listed above in gene's analysis unit (Cornell University, NY, USA sequencing facility center).

\section{Phylogenetic analysis}

Phylogenic data were obtained by aligning the nucleotides of different 16S rRNA retrieved from the Basic Local Alignment Search 
Tool (BLAST) algorithm available through the National Center for Biotechnology Information (NCBI) website (http://www.ncbi.nlm. nih.gov), using the CLUSTAL $\mathrm{W}$ program version 1.8 with standard parameters. Phylogenetic and molecular evolutionary analyses were conducted using MEGA 6. A rooted phylogram was derived from the distance matrices using the neighbor-joining method. All analyses were performed on a bootstrapped data set containing 500 replicates (generated by the program).

\section{Nucleotide sequence accession number}

The nucleotide sequences of the 16S rRNA gene of strain NRC-88 have been deposited in the GenBank database under accession number KM014489.

\section{Secondary structure prediction and restriction site analysis}

The RNA secondary structure of the isolate NRC-88 was predicted, according to Brodsky et al. [32] using GeneBee online software (http:// www.genebee.msu.su/services/rna2_reduced.html) by the greedy method and the restriction sites of the DNA of the strain was analyzed by NEB cutter Version 2.0 (http://tools.neb.com/NEBcutter2/) according to Vincze et al. [33].

\section{Bioassay determination method of CA}

CA production was determined by the specific synergistic bioassay according to Romero et al. [20] with some modifications according to Awad et al. [17] and Awad and El-Shahed [18]. The assay was carried out by agar well diffusion method using the Muller Hinton assay medium (Difco, MI., USA) supplemented with $(25 \mu \mathrm{g} / \mathrm{ml})$ Penicillin G. The test strain, Penicillin G resistant E. coli, (suspension at optical density $=1.0$ at $600 \mathrm{~nm}$ ), was used. Using a sterile cork borer, wells were punctured in appropriate agar medium plates previously seeded with the test organism. $100 \mu \mathrm{l}$ of the supernatant of each sample was administrated in each well. The agar plates were kept at $4^{\circ} \mathrm{C}$ for at least 30 minutes to allow the diffusion of the active metabolite to agar medium. The plates were then incubated at $37^{\circ} \mathrm{C}$. Pure CA kindly be provided by Glaxso SmithKline (Glaxo Wellcome UK Ltd., Middlesex, UK) was used as standard. The inhibition zone diameter was measured and converted to antibiotic concentration using a standard curve.

\section{Spectrophotometrically determination of CA}

The derivative of CA with imidazole was determined by spectrophotometer at $312 \mathrm{~nm}$ according to Bird et al. [22]. A $8.25 \mathrm{~g}$ of imidazole were dissolved in about $65 \mathrm{ml}$ of distilled water, adjusted to the $\mathrm{pH}$ at $6.8 \pm 0.05$ with $5 \mathrm{~mol} \mathrm{HCl}$ and dilute to $100 \mathrm{ml}$ with distilled water.

\section{CA detection by TLC}

CA was detected on TLC at $20^{\circ} \mathrm{C}$ using a solvent system consisting of n-butanol:ethanol:water (4:1:5, v/v/v, top phase). A dark red spot at $\mathrm{R}_{\mathrm{f}}=0.44$ appeared on the glass-coated chromatogram after spraying with 2, 3, 5-triphenyltetrazolium chloride reagent [21].

\section{CA assay by HPLC method}

CA concentration was determined by HPLC after derivatization with imidazole [23] with some modifications according to the optimum $\mathrm{pH}$ of imidazole $(6.8 \pm 0.05)$, using a Polaris column C-18 $(4.6 \mathrm{~mm} \times$ $250 \mathrm{~mm}, 5 \mu \mathrm{m})$. The mobile phase was composed of methanol and 0.1 mol $\mathrm{KH}_{2} \mathrm{PO}_{4}$ adjusted to $\mathrm{pH} 3.2$ with $\mathrm{H}_{3} \mathrm{PO}_{4}(6: 94)$ at a flow rate $1.5 \mathrm{ml} / \mathrm{min}$, on $28^{\circ} \mathrm{C}$. The assay was carried out using HPLC (SIKIM, Ammerbuch, Germany) and the peak was detected at $312 \mathrm{~nm}$ using ultraviolet (UV)/visible detector model UV-2070 Plus, (Jasco, Tokyo, Japan), while standard pure CA was prepared daily [18].

\section{RESULTS AND DISCUSSION}

\section{Soil sample and isolation}

The main goal of this study was to isolate and characterize a new Streptomyces strain with $\beta$-lactamase inhibitory activity of (New Valley locality) Egyptian soil. Isolation of Streptomyces sp.NRC-88 was carried out using different selective Streptomyces media such as an Actinomycetes isolation agar medium (Difco, NJ, USA) and Streptomyces medium according to our previous study by Awad et al. [17] and Awad and El-Shahed [18]. The enlargement of antifungal agents to the confinement media stifles the development of fungal species on the plates. For this purpose, either cycloheximide $(50-100 \mu \mathrm{g} / \mathrm{ml})$ or nystatin (10-50 $\mu \mathrm{g} / \mathrm{ml})$ was used [34]. On the other hand, Penicillin G was added to the medium to minimize the bacterial contamination.

In this work, five out of thirty isolates of Streptomyces sp. obtained showed noticeable inhibitory activity against E. coli resistant to Penicillin G. This inhibitory activity may be due to any substance inhibiting or degrading the $\beta$-lactam antibiotic. We selected the most active isolate (based on inhibition zone diameter) for further study. The selected strain was named NRC-88. The inhibitory activity of strain NRC-88 was tested using a specific synergistic biological assay against a resistant Gram-negative bacterium E. coli by utilizing a small amount of agar from 7-day-old culture developed on actinomycetes isolation agar medium as primary screening. The results of the primary screening showed a noticeable $\beta$-lactamase inhibitory activity against $E$. coli resistance bacterium. For the secondary screening, Streptomyces sp. NRC-88 was cultivated on submerged culture using a specific CA production medium for further investigation. After $6^{\text {th }}$ day cultivation, the supernatant was sterilized by filtration and used to determine the inhibitory activity. The CA yield was determined by specific synergistic bioassay, spectrophotometric assay, detected by TLC, and confirmed by HPLC assay of which the CA peak was at retention time of 3.22 minutes from a culture broth of strain NRC-88 and 3.525 minutes for standard pure CA (Fig. 1).

The maximal CA yield of $87 \mathrm{mg} / \mathrm{ml}$ was obtained. These obtained results were close to those quoted in the literature using the complex medium. For example, Chen et al. [35] obtained $115 \mathrm{mg} / \mathrm{l} \mathrm{CA}$ from the medium containing soy flour without any addition of amino acids. Neto et al. [36] obtained about $200 \mathrm{mg} / \mathrm{l}$ using the mixture of complex medium components of soy bean hydrolyzed protein, malt extract, and yeast extract in addition to other minerals. However, all these studies were conducted in a stirred tank bioreactor level with well-controlled conditions. Therefore, strain NRC-88 was submitted for identification.

The production medium that was used contains soy bean protein in the form of an extract. Several studies have shown the advantages of soy bean meal extract that is used in the production of both antibiotics generally and especially CA. One of these studies is Chen et al. [35], who observed that the highest CA production was obtained when soybean

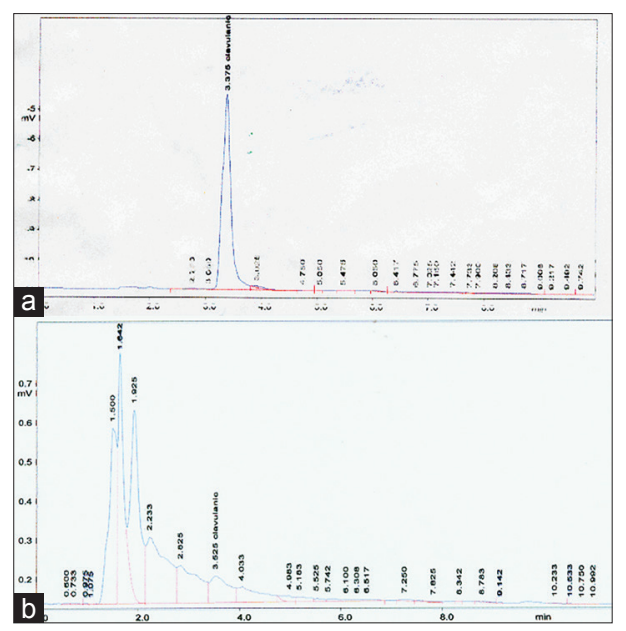

Fig. 1: Analytical high performance liquid chromatography chromatogram showing (a) pure Clavulanic acid (CA) standard at 3.375 minutes and (b) CA in fermented broth of strain NRC-88 at 3.525 minutes retention time 
flour was utilized. Another study was done by Rosa et al. [37], who mentioned that soy bean protein is the most important nutrient for the CA biosynthesis. The soybean meal used in the production medium seems to be effective for production of secondary metabolites because of the slow breakdown during the fermentation process. It provides proper cellular growth and contains arginine, the precursor of the CA molecule [38] and has been proven to be the safest high protein cereal grain to use in antibiotic production.

\section{Taxonomy of Streptomyces strain NRC-88 Conventional taxonomy}

Cultural and morphological characteristics

Strain NRC-88 propagated on a series of agar media with the different degrees in the growth, displaying morphology typical of Streptomyces [27], since the colony was slow growing, aerobic, white and layered, with an earthy odor, and aerial substrate mycelia of altered colors. The abundance and the color of aerial mycelium depended on the medium composition and the age of the culture. The growth was abundant on most of the used media but was moderate on ISP 2 and ISP7 media, but it is fair using an ISP 5 medium (Table 1). The color of aerial mycelium was white. Therefore, strain NRC-88 was assigned in the white series. The strain did not produce any diffusible pigment on most of the media used. While strain NRC-88 produced a soluble pigment, whose color was brown on ISP 5, Bennett's, ISP 7, and nutrient agar media, the color was yellowish on ISP 2 medium (Table 1). Culturing method and morphological characteristics were used as a method to identify Streptomyces species using the selective plating technique [39].

The morphology spore chains' of the strain NRC-88 was an open spiral type (Fig. 2a), and can be assigned in a spiral group. As indicated by the state of the spore chains seen under light microscopy, the isolates were gathered as rectus-flexibilities, spiral (S), and retinaculiaperti [27]. The spore surface ornamentation of strain NRC-88 was observed by TEM showing the smooth spore surface (Fig. 2b). Adopting from Shirling and Gottlieb [24] research facilities having admittance to an electron microscope must incorporate electron micrographs of the spore surface as one of the unmistakable portrayals for each type of culture.

Physiological and biochemical properties

Strain NRC-88 was tested on melanin pigment production media such as ISP 1,6 , and 7. It grew on these media, but no melanin pigment was observed on all the used media. The strain grew in the gelatin medium but could not liquefy the gelatin. Moreover, it grew on skimmed milk medium but did not cause coagulation and peptonization. Therefore, the NRC-88 strain did not harbor the respective degrading enzyme. The strain did not reduce nitrate to nitrite, and it hydrolyzed the starch (Table 2). With auxiliary identification, some physiological appeals, such as degradation of starch, gelatin, and decline of nitrate, are also well-thought-out to determine the species' taxonomy of novel isolates strains as commended by Rosselló-Mora and Amann [40].
Examination of the whole-cell hydrolyzate of strain NRC-88 exposed the occurrence of chemo type, I cell wall LL-DAP acid (Table 2). The incidence of chemo Type I, LL-DAP in the cell wall indicates that this strain is Streptomyces as identified by Lechevalier and Lechevalier [28], who recognized that cell wall composition investigation is one of the key chemotaxonomic appeals of Streptomyces identification. Strain NRC-88 was capable of consuming different C-sources (Table 2). The strain NRC- 88made abundant mycelium on the basal medium with, L-arabinose, L-rhamnose, D-galactose, rraffinose, D-mannitol, myo-inositol and maltose, while the strain grew moderately in the occurrence of D-xylose, fructose, salicin, sucrose, and cellobiose. The strain cultivates poorly on a medium having D-glucose.

\section{Comparison between strain NRC-88 and the references Streptomyces strains}

Based on the phenotypic assets, strain NRC-88 was classified in the genus Streptomyces. The classification of a Streptomyces species is predominantly based on the color of aerial and substrate mycelium, and soluble pigment, the shape, and ornamentation of the spore surface because of its constancy. The characteristics of this strain were compared to the known Streptomyces species in Bergey's Manual of Determinative Bacteriology $9^{\text {th }}$ edition [26] and Bergey's Manual of Systematic Bacteriology [27]. Strain NRC-88 does not resemble any known strain, but has similarity to Streptomyces species (Streptomyces ochraceiscleroticus, Streptomyces herbescens, and Streptomyces flocculus). These strains have the same aerial, and substrate mycelia colors, spore shapes, and physiological characters with some differences between them.

Strain NRC-88 differs from all the previous Streptomyces species in its characteristics, such as its inability to utilize of most tested sugars, and produces CA, unlike other species. As supported by Rosselló-Mora and Amann [40], carbon source usage, as an extra test was likewise

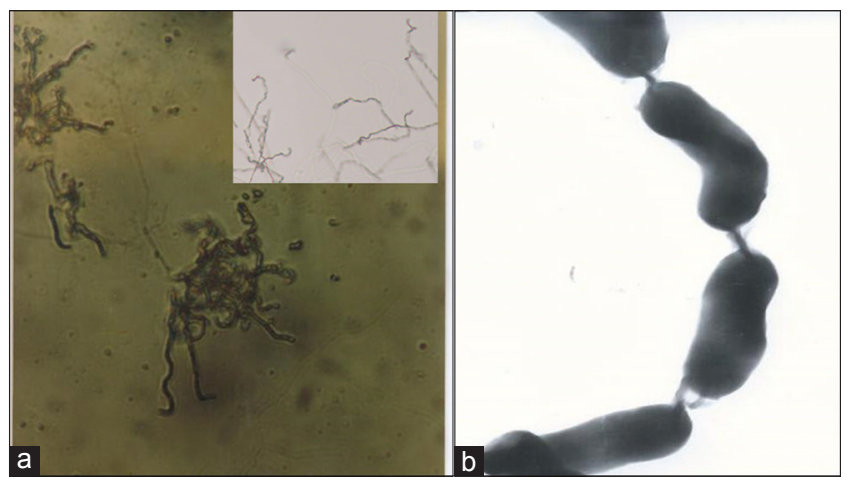

Fig. 2: Morphology of spore-bearing aerial mycelium of NRC-88 isolate, spore chains of the spiral type are shown, $\times 1.000$

(a) and Spore surface is shown as smooth, $\times \mathbf{4 0 . 0 0 0}$ (b) after 14 and 21 days of the incubation on Bennett's agar medium at $28^{\circ} \mathrm{C}$

Table 1: Cultural characteristics of NRC-88 strain

\begin{tabular}{|c|c|c|c|c|}
\hline \multirow[t]{2}{*}{ Agar medium } & \multirow[t]{2}{*}{ Amount of growth } & \multicolumn{2}{|c|}{ Color of } & \multirow[t]{2}{*}{ Soluble pigment } \\
\hline & & Arial mycelium & Substrate mycelium & \\
\hline Yeast extract-malt extract (ISP 2) & Moderate & Beige and white from edge & White cottony & Yellowish \\
\hline Oatmeal (ISP 3) & Abundant & White cottony & White-to-brownish & Brownish \\
\hline Inorganic salts-starch (ISP 4) & Abundant & $\begin{array}{l}\text { White cottony } \\
\text { hygroscopic }\end{array}$ & Beige-light yellow & None \\
\hline Glycerol-sparagine (ISP 5) & Fair velvety & White cottony hygroscopic & Yellowish & None \\
\hline Czapek's agar & Abundant & Chalk-white & Light-yellow & None \\
\hline Glucose-asparagine agar & Abundant & White cottony & Ivory or light-yellow & None \\
\hline Tyrosine agar (ISP 7) & Moderate & Chalk-white & White-light yellow & Brown \\
\hline Nutrient agar & Abundant & White cottony & White-to-brownish & Brown \\
\hline
\end{tabular}

ISP: International Streptomyces Project 
Table 2: Physiological, morphological, biochemical properties and amino acids utilization of NRC-88 strain

\begin{tabular}{|c|c|c|c|}
\hline Character & Results & Character & Utilization \\
\hline Morphological characteristic & & N-Source & \\
\hline Spore chains & Spirals & DL-methionine & Poor growth \\
\hline Spore surface & Smooth & DL-Iso-leucine & Weak growth \\
\hline Color of aerial mycelium & White & L-arginine & Weak growth \\
\hline Physiological characteristics & & L-lysine & Abundant growth \\
\hline Hydrolysis of starch & Positive & L-glutamic & No growth \\
\hline Action of milk & No coagulation in 14 days & L-histidine & Poor growth \\
\hline Nitrate reduction & Negative & Ph-alanine & Abundant growth \\
\hline Gelatin liquefaction & None & L-aspargine & Weak growth \\
\hline Melanin production & None & L-valine & Weak growth \\
\hline Cell wall hydrolysis & & L-cystaine & No growth \\
\hline LL DAP & Positive & Glycine & Good growth \\
\hline Sugar pattern & ND & Proline & Weak growth \\
\hline \multirow{2}{*}{ Utilization of C-source } & & Ornithine & Weak growth \\
\hline & & Tyrosine & Good growth \\
\hline D-glucose & + & DL-serine & Moderate growth \\
\hline D-xylose & ++ & Antibiotics susceptibility (mm) & \\
\hline L-arabinose & +++ & $(\mathrm{RD} 5 \mu \mathrm{g})$ & 00 \\
\hline L-rhamnose & +++ & (VA $30 \mu \mathrm{g}$ ) & 20 \\
\hline D-fructose & ++ & (S $10 \mu \mathrm{g})$ & 15 \\
\hline D-galactose & +++ & (N $30 \mu \mathrm{g})$ & 12 \\
\hline Raffinose & +++ & (TE $5 \mu \mathrm{g}$ ) & 18 \\
\hline D-mainitol & +++ & (NA $30 \mu \mathrm{g}$ ) & 06 \\
\hline Meso-inositol & +++ & (NV $30 \mu \mathrm{g})$ & 00 \\
\hline Salicin & ++ & (CDZ $30 \mu \mathrm{g})$ & 22 \\
\hline Sucrose & ++ & Resistance toward sodium chloride (\%) & \\
\hline Cellobiose & ++ & 0 & Weak \\
\hline Maltose & +++ & 2 & Abundant \\
\hline Temperature tolerance $\left({ }^{\circ} \mathrm{C}\right)$ & & 4 & Moderate \\
\hline $28-37$ & Abundant & 7 & Weak \\
\hline
\end{tabular}

+: Weak growth, ++: Modrate growth, +++: Abundant growth, DAP: Diaminopimelic acid, RD: Rifamycin, VA: Vancomycin, S: Streptomycin, N: Neomycin, TE: Tetracycline, NA: Nalidixic acid, NV: Novobiocin, CDZ: Cefodizime

considered to discover species arrangement of a new isolates strain. The ordered grouping, and recognizable proof of a Streptomyces species in light of morphological, physiological, and biochemical portrayals is troublesome and not adequate [41]. In this manner, genotypic approaches illustrate an enhancement and have been utilized to distinguish a few recently isolated Streptomyces [42].

Molecular identification and phylogenetic analysis of strain NRC-88 PCR amplification and primer specificity

The experimental analysis of the PCR amplification performance of the forward primer StrepB in combination with the reverse primer StrepF was accompanied by the reaction conditions pronounced in materials and methods. The specificity of the PCR is affected by numerous factors, particularly the primer pairs. In this study, the (StrepB/StrepF) primer pair was used as a specific primer for Streptomyces. The primer was studied by PCR amplification using genomic DNA, isolated from strain NRC-88. The primers were positively used to amplify genomic DNA from the isolated samples. These results are in agreement with Rintala et al. [30], who showed that these primers are specific for Streptomyces.

Sequencing and phylogenetic analysis

The nucleotide sequence ( $466 \mathrm{bp}$ ) of strain NRC-88 was subjected to match with the 16S rRNA reported gene sequences in the gene bank database. The database of NCBI BLAST available at (www.ncbi-nlmnih.gov/BLAST) was used to compare the strain NRC-88 with those of member Streptomyces species strains. Due to the high sequence similarity of the species (99\%) with Streptomyces strains, strain NRC88 is most closely related to S. aburaviensis S-66. However, they have the highest similarity on a genetic level, show differences on some phenotypic level. Furthermore, they are not different in their CA productivity, but in thier ability to produce CA.

A taxonomy that has been founded on restricted phenotypic and hereditary criteria are changing, regularly and fundamentally, since

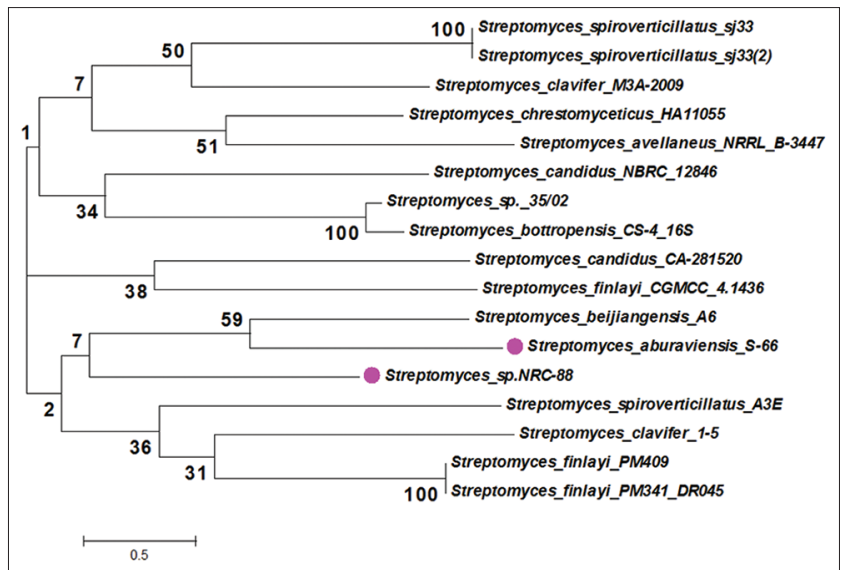

Fig. 3: Neighbor-joining phylogenetic representation of the strains and their closest National Center for Biotechnology Information relatives based on $16 \mathrm{~S}$ rRNA gene sequences of Streptomyces sp. NRC-88 and some known sequences of Streptomyces

new phylogenetic in view of $16 \mathrm{~S}$ rDNA sequence information give significant data about Streptomyces. Systematic techniques have turned out to be accessible at lower taxonomic levels as well as at the division and order levels utilized in identifying a few recently isolated Streptomyces $[43,44]$.

In the alignment of the phylogenetic tree, all the unclassified and classified Streptomyces strains, which were most different from strain NRC-88 in terms of phenotypic characteristics, were discarded. A phylogenetic tree resulted from the distance matrices using a neighbor-joining method (Fig. 3). 
A good similarity was found between the 16S rRNA sequence of S. aburaviensis S-66 and strain NRC-88. In contrast, variations were found between the binary similarity of the $16 \mathrm{~S}$ rRNA gene sequence of strain NRC-88 and the 16S rRNA gene sequences of all other Streptomyces strains matching on the GenBank database that had a similarity of $99 \%$ as shown in Table 3 .

\section{Polysporic approach}

There exist some differences in the morphological, biochemical and physiological characters of strain NRC-88 and the neighbors S. ochraceiscleroticus, S. herbescens, S. flocculus and S. aburaviensis S-66, especially in the utilization of most sugar used as shown in Table 4.

Owing to these differences, S. aburaviensis S-66 produces other metabolites like antifungal antibiotics and an enzyme inhibitor [45]. On the other hand, S. ochraceiscleroticus produces xylanase, celulases and antitumor antibiotic. While, S. flocculus produces streptonigrin, the benzoquinone antibiotic shows immunosupressant, antineoplastic, antiHIV and antileukaemic activity. The lowest binary similarity between strain NRC-88 and the CA producer strains such as S. clavuligerus, $S$. jumonjinensis, and $S$. katsurahamanus was recorded. Antibiotic production by actinomycetes, therefore, may not be species-specific but strain-specific [46]. However, CA is no antibiotic, but a secondary metabolite acting as a potent $\beta$-lactamase inhibitor. Furthermore, the Streptomyces sp. NRC-88 strain is known to produce CA but is a different strain from S. clavuligerus as the reference strain of CA.
It is clear from phylogenetic investigation that, strain NRC-88 speaks to an unmistakable phyletic line recommending another genomic species. It is obvious from Table 4 that strain NRC-88 can be recognized from the type strains of its most prompt phylogenetic neighbors of the family Streptomyces by its phenotypic and phylogenetic characterization. The use of genotypic and phenotypic systems (polysporic approach) gives a superior resolution in the species level identification proof (Mizui et al.) [47]. It is clear from the genotypic and phenotypic information that strain NRC-88 should be perceived as the type strain of a novel species in the genus Streptomyces. The name proposed for this taxon is Streptomyces sp. NRC-88 nova species. It is a potential source of active compounds.

Secondary structure prediction and Restriction site analysis The RNA secondary structure was predicted for 16S rRNA of Streptomyces sp. NRC-88 (Fig. 4). It showed that the free energy of structure is $-100.6 \mathrm{kkal} / \mathrm{mol}$, threshold energy is -4.0 with cluster factor, conserved factor 2 and compensated factor 4 and conservativity is 0.8 . The prediction of restriction sites of the strain NRC-88 showed the restriction sites for various enzymes such as Bsaw l, SnaBl, Eco53ktse1, PspGl and BsaHl, etc. (Fig. 5).

\section{CONCLUSION}

The novel Streptomyces, NRC-88 strain, was confined from an Egyptian soil sample that was equipped for creating CA. It had biochemical,

Table 3: Streptomyces sp. NRC-88 and its closest phylogenetic neighbors as representatives of Streptomyces species

\begin{tabular}{lll}
\hline S.No. & Strain name & Accession number \\
\hline 1 & Streptomyces sp. 35/02 & AY571804 \\
2 & Streptomyces spiroverticillatus sj33 & JX013967 \\
3 & Streptomyces chrestomyceticus HA11055 & JQ799044 \\
4 & Streptomyces candidus NBRC 12846 & NR__112302.1 \\
5 & Streptomyces clavifer 1-5 & KJ571024 \\
6 & Streptomyces clavifer M3A-2009 & KC469956 \\
7 & Streptomyces spiroverticillatus A3E & JX570583 \\
8 & Streptomyces candidus CA-281520 & JX840962 \\
9 & Streptomyces beijiangensis A6 & JX122145 \\
10 & Streptomyces finlayi PM409 & JQ422174 \\
11 & Streptomyces finlayi PM341_DR045 & JQ422171 \\
12 & Streptomyces finlayi CGMCC 4.1436 & JQ806133 \\
13 & Streptomyces bottropensis CS-4 16S & 99 \\
14 & Streptomyces avellaneus NRRL B-3447 & 99 \\
15 & Streptomyces aburaviensis S-66 & 99 \\
\hline
\end{tabular}

Table 4: Characteristics that separate strain NRC-88 from the type strains of phenotypically and phylogenetically closely related Streptomyces species

\begin{tabular}{|c|c|c|c|c|c|}
\hline \multirow[t]{2}{*}{ Bergey's taxonomy } & $\begin{array}{l}\text { Streptomyces sp. } \\
\text { NRC-88 }\end{array}$ & $\begin{array}{l}\text { Streptomyces } \\
\text { ochraceiscleroticus }\end{array}$ & $\begin{array}{l}\text { Streptomyces } \\
\text { herbescens }\end{array}$ & $\begin{array}{l}\text { Streptomyces } \\
\text { flocculus }\end{array}$ & \multirow{2}{*}{$\begin{array}{l}\text { Streptomyces aburaviensis } \\
\text { Similarity } 99 \% \text { from phylogenetic } \\
\text { tree [W; RF; C-; SM] }\end{array}$} \\
\hline & \multicolumn{4}{|c|}{ Similarity from phenotypic characterization $\left[\mathrm{W} ; \mathrm{S} ; \mathrm{C}^{-} ; \mathrm{SM}\right]$} & \\
\hline \multicolumn{6}{|l|}{ Sugar utilization } \\
\hline No sugar & - & - & - & - & - \\
\hline D-glucose & + & + & + & + & + \\
\hline L-arabinose & + & + & + & + & - \\
\hline L-rahamnose & + & + & + & + & - \\
\hline D-fructose & + & + & $?$ & + & \pm \\
\hline D-galactose & + & + & + & + & - \\
\hline Raffinose & - & + & + & + & - \\
\hline D-mannitol & + & + & + & + & - \\
\hline Myoinositol & + & + & + & + & - \\
\hline Salicin & + & + & $?$ & + & - \\
\hline
\end{tabular}

+: Positive utilization, \pm : Doubtful utilization, -: Negative utilization, ?: Not detected, W: White series by light microscope, S: Spiral spore surface, RF: Rectiflexibiles,

$\mathrm{C}^{-}:$Melanin negative, SM: Smooth spore chains by transmission electron microscope 


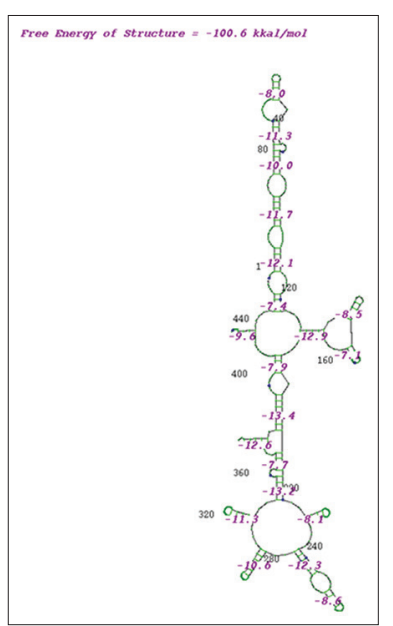

Fig. 4: Secondary structure prediction of 16s rRNA of the strain Streptomyces sp. NRC-88 was done using GeneBee online software

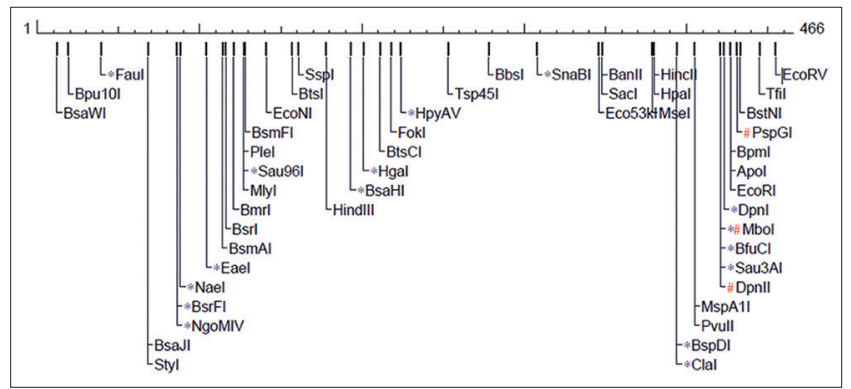

Fig. 5: Restriction sites of the strain Streptomyces $s p$. NRC-88 were predicted using NEB cutter

chemotaxonomic, morphological, and physiological attributes that were predictable with the genus Streptomyces. The closest Streptomyces strain was $S$. aburaviensis. Moreover, phylogenetic investigation of the 16S rRNA quality succession of strain NRC-88 has a high similarity of $99 \%$ of S. aburaviens, but has variation in its morphological propertiesis. In view of this information, strain NRC-88 is a novel species of genus Streptomyces, and we proposed the name Streptomyces sp. NRC-88 sp. nov., (accession number KM014489). This strain produced up to $87 \mathrm{mg} / \mathrm{L}$ of CA.

\section{REFERENCES}

1. Alanis AJ. Resistance to antibiotics: Are we in the post-antibiotic era? Arch Med Res 2005;36(6):697-705.

2. Page MG. Beta-lactamantibiotics. In Antibiotic Discovery and Development. In: Dougherty TJ, Pucci MJ, editors. NewYork, NY: Springer; 2012. p. 79-117.

3. Shahid M, Sobia F, Singh A, Malik A, Khan HM, Jonas D, et al. Betalactams and beta-lactamase-inhibitors in current-or potential-clinical practice: A comprehensive update. Crit Rev Microbiol 2009;35(2):81-8.

4. Neu HC. The crisis in antibiotic resistance. Science 1992;257(5073):1064-73.

5. Toussaint KA, Gallagher JC. ß-lactam/ß-lactamase inhibitor combinations: From then to now. Ann Pharmacother 2015;49(1):86-98.

6. Saudagar PS, Survase SA, Singhal RS. Clavulanic acid: A review. Biotechnol Adv 2008;26(4):335-51.

7. Gor P, Ajbani A, Dalal K. Use of fixed dose combinations of antibiotics in a surgical department of a tertiary care teaching hospital alpa. Int J Pharm Pharm Sci 2015;7(11):259-62.

8. Demain AL, Sanchez S. Microbial drug discovery: 80 years of progress. J Antibiot (Tokyo) 2009;62(1):5-16.

9. Lazzarini A, Cavaletti L, Toppo G, Marinelli F. Rare genera of actinomycetes as potential producers of new antibiotics. Antonie Van Leeuwenhoek 2000;78(3-4):399-405.

10. Tan LT, Ser HL, Yin WF, Chan KG, Lee LH, Goh BH. Investigation of antioxidative and anticancer potentials of Streptomyces sp. MUM256 isolated from Malaysia mangrove soil. Front Microbiol 2015;6:1316.

11. Sathya R, Ushadevi T. Industrially important enzymes producing Streptomyces species from mangrove sediments. Int J Pharm Pharm Sci 2014;6(10):233-7.

12. Brown AG, Butterworth D, Cole M, Hanscomb G, Hood JD, Reading C, et al. Naturally-occurring beta-lactamase inhibitors with antibacterial activity. J Antibiot (Tokyo) 1976;29(6):668-9.

13. Jensen SE, Paradkar AS. Biosynthesis and molecular genetics of clavulanic acid. Antonie Van Leeuwenhoek 1999;75(1-2):125-33.

14. Cook MA, Wilkins RB. Process for the Preparation of Potassium Clavulanate; EP0672669B1; 1997.

15. Kitano K, Kintaka K, Katamoto K. Clavulanic acid production by Streptomyces katsurahamanus. Chem Abstr 1979;90:119758b.

16. Ocean Co. Ltd. (1981). Clavulanic Acid. Chem Abstr 94:137-803z.

17. Awad HM, El-Shahed KY, El-Nakkadi AE. Isolation, screening and identification of newly isolated soil Streptomyces (Streptomyces sp. NRC-35) for $\beta$-lactamase inhibitor production. World Appl Sci J 2009;7(5):637-46.

18. Awad HM, El-Shahed KY. A novel Actinomycete sp. isolated from Egyptian soil has $\beta$-lactamase inhibitor activity and belongs to the Streptomyces rochei phylogenetic cluster. World Appl Sci J 2013;3:360-70.

19. Guda IS, Abdelwahed NA, Awad HM, Shallan MA, El-Shahed KY, Abdel-Rahim AE. Enhancement of clavulanic acid production by Streptomyces sp. Mu-NRC77 via mutation and medium optimization. Trop J Pharm Res 2017;16(1):31-42.

20. Romero J, Liras P, Martin JF. Dissociation of cephamycin and clavulanic acid biosynthesis in Streptomyces clavuligerus. Appl Microbiol Biotechnol 1984;20:318-25.

21. Reading C, Cole M. Clavulanic acid: A beta-lactamase-inhiting betalactam from Streptomyces clavuligerus. Antimicrob Agents Chemother 1977;11(5):852-7.

22. Bird AE, Bellis JA, Gasson BC. Spectrophotometric assay of clavulanic acid by reaction with imidazole. Analyst 1982;107:1241-5.

23. Foulstone M, Reading C. Assay of amoxicillin and clavulanic acid, the components of Augmentin, in biological fluids with highperformance liquid chromatography. Antimicrob Agents Chemother 1982;22(5):753-62.

24. Shirling EB, Gottlieb D. Methods for characterization of Streptomyces species. Int J Syst Bacteriol 1966;16(3):313-40.

25. Tresner HD, Backus EJ. System of color wheels for Streptomyces taxonomy. Appl Microbiol 1963;11:335-8.

26. Holt JG, Krieg NR, Sneath PH, Staley JT, Williams ST. Bergey's Manual of Determinative Bacteriology. 9 $^{\text {th }}$ ed. Baltimore: Williams \& Wilkins; 2000

27. Locci R. Streptomycetes and related genera. In: Williams ST, Sharpe ME, Holt JG, editors. Bergey's Manual of Systematic Bacteriology. Vol. 4. Baltimore: The Williams, Wilkins Co.; 1989. p. 2451-508.

28. Lechevalier MP, Lechevalier HA. The chemotaxonomy of actinomycetes. Actinomycete Taxonomy. In: Dietz A, Thayer DW, ediors. Vol. 6. Arlington SIM, USA: Special Publication; 1980. p. 227-91

29. Lee YK, Kim HW, Liu CL, Lee HK. A simple method for DNA extraction from marine bacteria that produce extracellular materials. J Microbiol Methods 2003;52(2):245-50.

30. Rintala $\mathrm{H}$, Nevalainen A, Rönkä E, Suutari M. PCR primers targeting the 16S rRNA gene for the specific detection of Streptomycetes. Mol Cell Probes 2001;15(6):337-47.

31. Kim J, Lee J. Cloning, DNA sequence determination and analysis of growth-associated expiration of the SodF gene coding for Fe- and $\mathrm{Zn}$ containing superoxide dismutase of Streptomyces griseous. J Microbiol Biotechnol 2000;10:700-6.

32. Brodskii LI, Ivanov VV, Kalaidzidis IaL, Leontovich AM, Nikolaev VK, Feranchuk SI, et al. GeneBee-NET: An internet based server for biopolymer structure analysis. Biokhimiia 1995;60(8):1221-30.

33. Vincze T, Posfai J, Roberts RJ. NEBcutter: A program to cleave DNA with restriction enzymes. Nucleic Acids Res 2003;31(13):3688-91.

34. Kathiresan K, Balagurunathan R, Masilamaiselvam M. Fungicidal activity of marine actinomycetes against phyotopathogenic fungi. Ind J Bioethanol 2005;4:271-6.

35. Chen KC, Lin HY, Wu JY, Hwang SC. Enhancement of clavulanic acid production in Streptomyces clavuligerus with ornithine feeding. Enzyme Microb Technol 2003;32:152-6.

36. Neto AB, Hirata DB, Cassiano Filho LC, Bellao C, Badino Junior AC, Hokka CO. A study on clavulanic acid production by Streptomyces 
clavuligerus in batch, fed-batch and continuous processes. Braz J Chem Eng 2005;22(4):557-63.

37. Rosselló-Mora R, Amann R. The species concept for prokaryotes. FEMS Microbiol Rev 2001;25(1):39-67.

38. Chen K, Lin Y, Tsai C, Hsieh C, Houng J. Optimization of glycerol feeding for clavulanic acid production by Streptomyces clavuligerus with glycerol feeding. Biotechnol Lett 2002;24:455-8

39. Williams ST, Goodfellow M, Wellington EM, Vickers JC, Alderson G, Sneath $\mathrm{PH}$, et al. A probability matrix for identification of some Streptomycetes. J Gen Microbiol 1983;129(6):1815-30.

40. Rosa JC, Baptista Neto A, Hokka CO, Badino AC, Influence of dissolved oxygen and shear conditions on clavulanic acid production by Streptomyces clavuligerus. Bioprocess Biosyst. Eng. 2005; 27:99-104.

41. Anderson AS, Wellington EM. The taxonomy of Streptomyces and related genera. Int J Syst Evol Microbiol 2001;51:797-814.

42. Kim J, Lee J. Cloning, DNA sequence determination, and analysis of growth-associated expiration of the SodF gene coding for Fe-and $\mathrm{Zn}$ containing superoxide dismutase of Streptomyces griseous. J Microbiol Biotechnol 2000;10:700-6

43. Bull AT, Ward AC, Goodfellow M. Search and discovery strategies for biotechnology: The paradigm shift. Microbiol Mol Biol Rev 2000;64(3):573-606

44. Kim HJ, Lee SC, Hwang BK. Streptomyces cheonanensis sp. nov. a novel streptomycete with antifungal activity. Int J Syst Evol Microbiol 2006;56:471-5.

45. Raytapadar S, Paul AK. Production of an antifungal antibiotic by Streptomyces aburaviensis 1DA-28. Microbiol Res 2001;155(4):315-23.

46. Jensen PR, Williams PG, Oh DC, Zeigler L, Fenical W. Species-specific secondary metabolite production in marine actinomycetes of the genus Salinispora. Appl Environ Microbiol 2007;73(4):1146-52.

47. Mizui Y, Sakai T, Iwata M, Uenaka T, Okamoto K, Shimizu H, et al. Pladienolides, new substances from culture of Streptomyces platensis Mer-11107. III. In vitro and in vivo antitumor activities. J Antibiot (Tokyo) 2004;57(3):188-96 